\title{
Distinctive Features of Altitude-velocity Characteristics of Detonation Gas Turbine Engines
}

\author{
Andrey Tkachenko, Viktor Rybakov and Evgeny Filinov \\ Samara National Research University, Department of Aircraft Engine Theory, Samara, Russian Federation
}

\begin{abstract}
The paper describes the distinctive features of the altitude-velocity characteristics of detonation gas turbine engines. The necessity of developing a new type of gas turbine engines is substantiated and the main features of detonation engines are described. The principal constructive scheme of detonation gas turbine engines is presented. Developed the one-dimensional mathematical model of detonation gas turbine engine. This model describes a working process in a gas generator and a traction module. Its verification with a real prototype is performed. A number of studies were carried out using the developed mathematical model. A comparison of the pulsating engine with the classic afterburner was performed. From the obtained results it is concluded that detonation engines are more economical than the engines of traditional schemes. It was also revealed that it is possible to obtain a range of flight speeds depending on a certain height only by adjusting the gas generator according to different control laws. In this regard, the purpose of further work will be the development of a three-dimensional mathematical model of the detonation engine and the creation on its basis of a stand of virtual tests for further research.
\end{abstract}

\section{Nomenclature}

$F \quad$ thrust, $[\mathrm{kN}]$;

$H \quad$ flight altitude, [km];

$M \quad$ Mach number;

$n \quad$ rotation speed, [\%];

$n_{s p} \quad$ specific rotation speed, [\%];

$p_{\text {air }}$ air pressure, $[\mathrm{Pa}]$;

$p_{c}^{*} \quad$ compressor delivery stagnation pressure, $[\mathrm{Pa}]$;

$p_{p m}^{*} \quad$ power module inlet stagnation pressure, $[\mathrm{Pa}]$;

$S F C$ specific fuel consumption, $\left[\mathrm{kg} /\left(\mathrm{kN}^{*} \mathrm{~h}\right)\right]$;

$T_{G}^{*} \quad$ turbine inlet stagnation temperature, $[\mathrm{K}]$;

$\pi_{C}^{*} \quad$ compressor pressure ratio;

$\pi_{V} \quad$ impact air pressure ratio;

$\sigma_{\text {in }} \quad$ loss coefficient of stagnation pressure in inlet;

$\sigma_{\text {pas }}$ loss coefficient of stagnation pressure in bleed-off passage from compressor to power module.

\section{Introduction}

In the last decade, the rate of improvement of the gas turbine engines specific parameters significantly decreased [1-3]. This is because engines have almost reached the limit of their capabilities (so-called "thermodynamic saturation"), and further progress will be associated with considerable difficulties and will take place on the evolutionary path, i. e. due to the improvement of design decisions. For the revolutionary development of engines need to implement innovative solutions. One such solution is the development of engines operating on the principle of detonation fluid energy conversion. Different sources proved that the thermal efficiency of the cycle with a supply of heat at constant volume (i.e., via detonation combustion) is greater than Brayton cycle efficiency (with the supply of heat at constant pressure). Thus, the development of pulse detonation engines is an actual and important task [4-10].

A pulse detonation engine, or "PDE" (figure 1 and figure 2), is a type of propulsion system that uses detonation waves to combust the fuel and oxidizer mixture. The engine is pulsed because the mixture must be renewed in the combustion chamber between each detonation wave initiated by an ignition source. Theoretically, a PDE can operate from a subsonic up to a hypersonic flight speed of approximately Mach 5. An ideal PDE design can have a thermodynamic efficiency higher than other designs like turbojets and turbofans because a detonation wave rapidly compresses the mixture and adds heat at a constant volume .

To date, no practical PDE has been put into production, but several testbed engines have been built in the low-speed demonstration aircraft that flew in sustained PDE powered flight in 2008.

Detonation turbines for higher efficiency power generation. Pratt and Whitney is developing a new combustor for gas turbine engines that uses shockwaves for more efficient combustion through a process known as continuous detonation. GE has also been working on pulse detonation. 


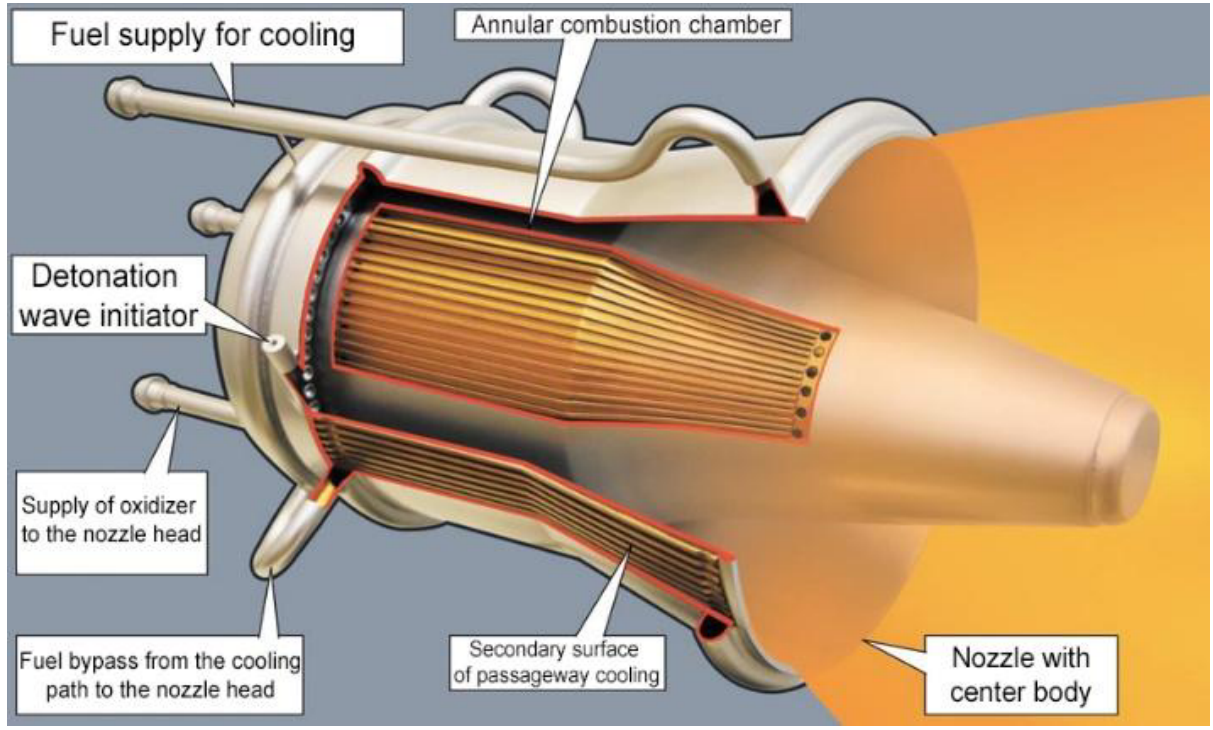

Figure 1. A pulse detonation engine
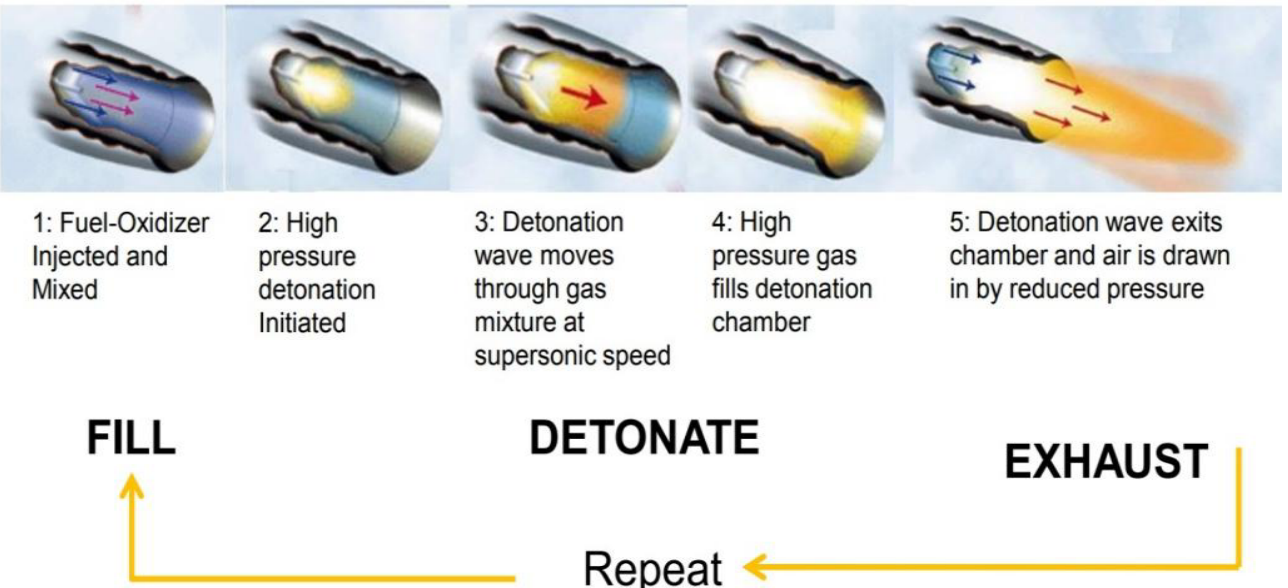

\section{DETONATE}

Repeat

Figure 2. Fundamentals of Pulse Detonation Engine (PDE)

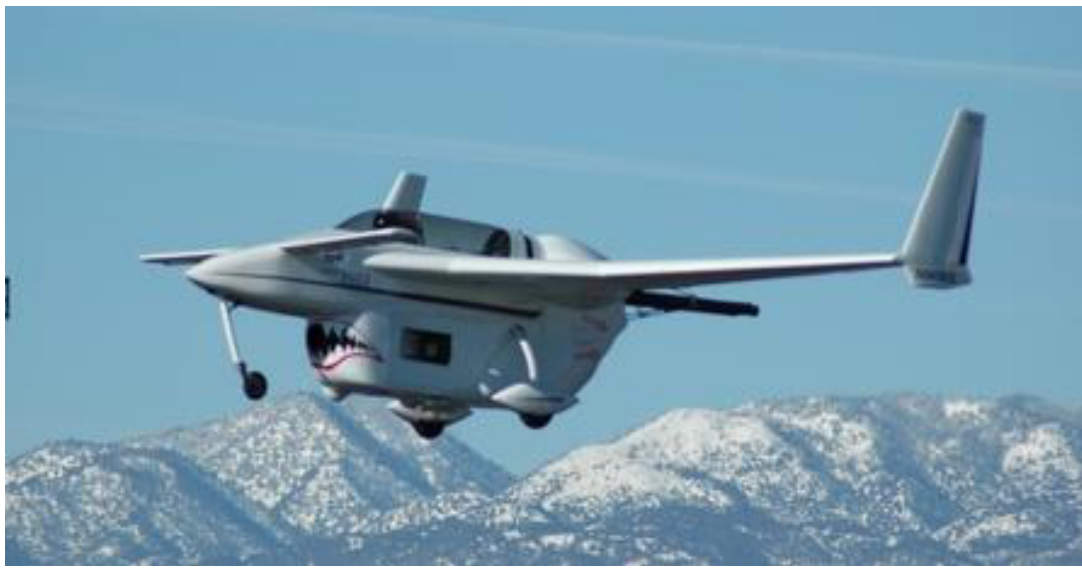

Figure 3. In-flight picture of the pulsed detonation powered, and heavily modified, Rutan Long-EZ.

Airbus is researching the continuous detonation wave engine. The continuous detonation wave engine (CDWE) is a radical new technology which could offer significantly more efficient and capable propulsion systems for civil aircraft - with expectations to deliver substantial fuel savings while reducing emissions.
When fitted to a conventional jet engine, CDWE technology offers to transform overall engine performance and simplify its design by using detonation waves to combust the fuel and oxidizer mixture. Theoretically, this system can operate from subsonic up to a hypersonic flight speed of roughly Mach 5, with higher efficiency than designs such as turbojets and 
turbofans. This is because a detonation wave rapidly compresses the mixture and adds heat at constant volume-providing a thermal efficiency improvement of approximately 25 percent [11].

The first known flight of an aircraft powered by a pulse detonation engine took place at the Mojave Air \& Space Port on 31 January 2008.[12] The project was developed by the Air Force Research Laboratory and Innovative Scientific Solutions, Inc.. The aircraft selected for the flight was a heavily modified Scaled Composites Long-EZ, named Borealis. The engine consisted of four tubes producing pulse detonations at a frequency of 80 $\mathrm{Hz}$, creating up to 200 pounds of thrust (890 newtons). Many fuels were considered and tested by the engine developers in recent years, but a refined octane was used for this flight. A small rocket system was used to facilitate the liftoff of the Long-EZ, but the PDE operated under its own power for 10 seconds at an altitude of approximately 100 feet $(30 \mathrm{~m})$. Obviously, this flight took place at a low speed whereas the appeal of the PDE engine concept lies more at high speeds, but the demonstration showed that a PDE can be integrated into an aircraft frame without experiencing structural problems from the 195-200 dB detonation waves. No more flights are planned for the modified Long-EZ, but the success is likely to fuel more funding for PDE research. The aircraft itself has been moved to the National Museum of the United States Air Force for display (figure 3) [13].

\section{Problem description}

Detonation gas turbine engine generally consists of a compressed air generator and power module (figure 4). Compressed air generator is for supplying compressed air to the desired pressure and power module operates as a conventional turbojet engine - the cycle with constant pressure heat supply. The difference is that it is not intended to generate shaft power or thrust jet, but serves only as a source of compressed air taken from the compressor.

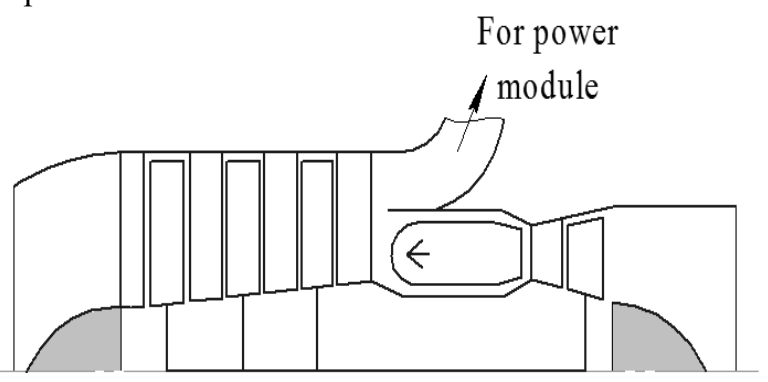

Figure 4. Scheme of detonation gas turbine engine.

Distinctive features of detonation gas turbine engine are that the input to the power module (at the outlet of the compressor of the gas generator) in the whole range is necessary to provide constant pressure:

$p_{p m}^{*}=p_{c}^{*} \cdot \sigma_{\text {pas }}=p_{\text {air }} \cdot \pi_{V} \cdot \sigma_{\text {in }} \cdot \pi_{C}^{*} \cdot \sigma_{\text {pas }}=$ const . (1)

This condition has a very significant influence on the characteristics of detonation gas turbine engine. For example, the environmental conditions at constant compressor pressure ratio are kept constant. In this case, the impact air pressure ratio $\pi_{V}$ is uniquely determined by altitude, i.e. airspeed can not be taken as an independent variable. The same can be said about the flight altitude at a certain airspeed.

\section{Calculations}

In this work a mathematical model of detonation gas turbine engine is formed in CAE-system "ASTRA" [14, 15]. This model describes the work of the gas generator and power module. The object of research is the detonation gas turbine engine with overall pressure ratio 4.3 and inlet turbine temperature $1300 \mathrm{~K}$.

For this engine, three altitude-speed characteristics for three laws of control were calculated ( $n=$ const, $n_{s p}=$ const and $T_{G}^{*}=$ const $)$. Each of these laws provides a constant pressure at the inlet of the power module.

Results of calculation are presented at figure 5. As can be seen from these results, receive depending flight range of speeds at a certain height is only possible at the expense of control gas generator on various control laws.

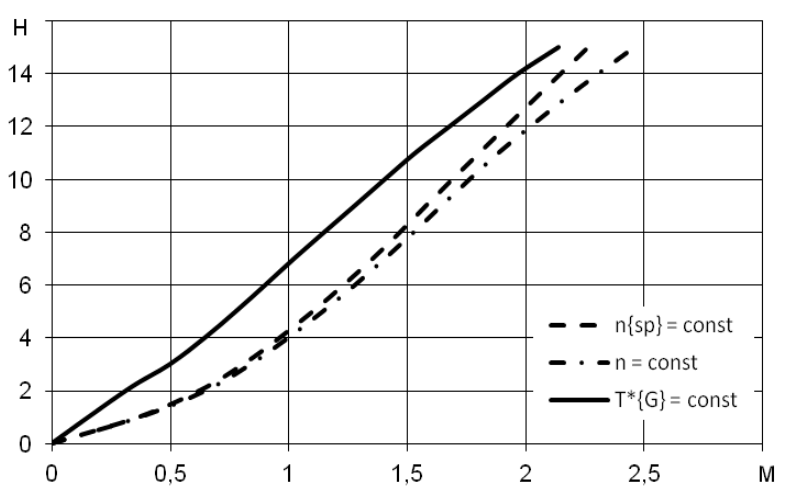

Figure 5. Altitude-velocity characteristics of detonation gas turbine engine.

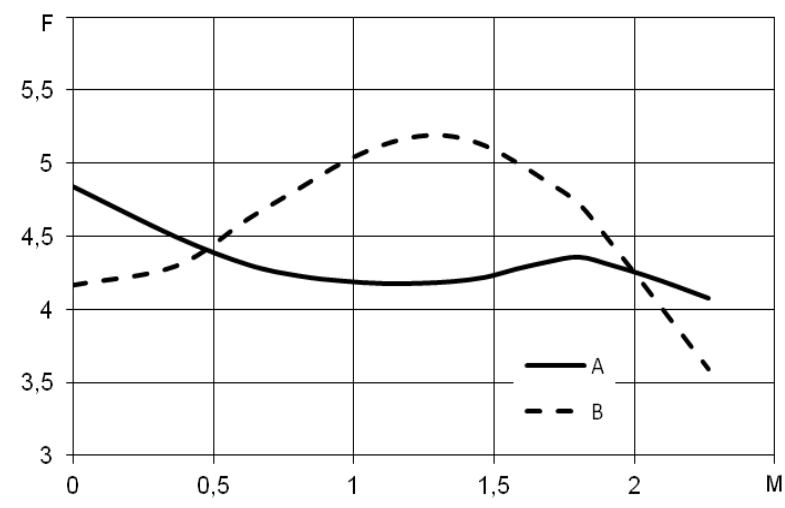

Figure 6. Velocity characteristics of detonation gas turbine engine (A) and turbojet with afterburner (B).

Next comparison the detonation gas turbine engine and the turbojet with afterburner with same cycle parameters was performed.

Figure 6 shows the dependence of the thrust of the airspeed for the two study types of engines. It can be seen that the speed of flight $\mathrm{M}<0.5$ and $\mathrm{M}>2.0$ the detonation 
gas turbine engine has large trust. However, throughout the flight range of speeds detonation gas turbine engine has significantly lower specific fuel consumption (Figure. 7).

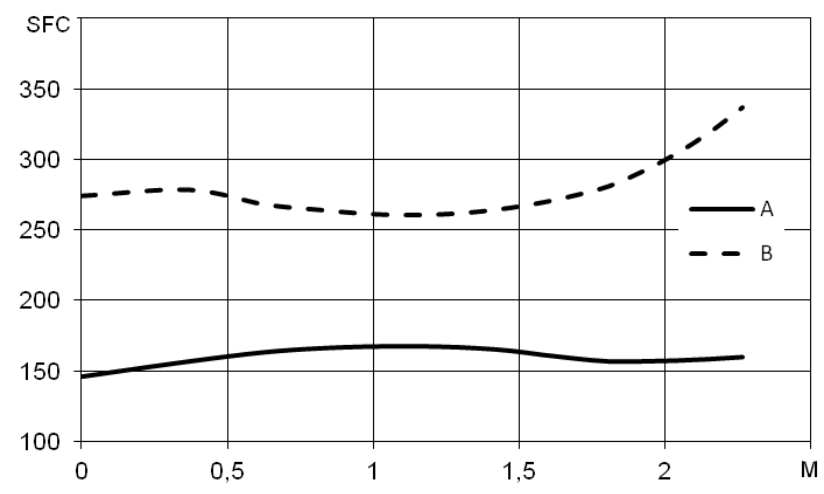

Figure 7. Velocity characteristics of detonation gas turbine engine (A) and turbojet with afterburner (B).

\section{Conclusion}

A one-dimensional mathematical model of the detonation engine describing the working processes in the gas generator and the traction module was formed, its verification with a real prototype was performed. A number of studies were carried out using the generated mathematical model. A comparison of the detonation engine with the classic afterburner was performed. From the obtained results it is concluded that detonation engines are more economical than the engines of traditional schemes. It was also revealed that it is possible to obtain a range of flight speeds depending on a certain height only by adjusting the gas generator according to different control laws. In this regard, the purpose of further work will be the development of a threedimensional mathematical model of the pulsing engine and the creation on its basis of a stand of virtual tests for further research.

\section{Acknowledgment}

This work was supported by the Ministry of education and science of the Russian Federation in the framework of the implementation of the Program of increasing the competitiveness of Samara University among the world's leading scientific and educational centers for 2013-2020 years.

\section{References}

1. I.N. Krupenich, E.P. Filinov, Y.A. Ostapyuk, A.Yu. Tkachenko, IJMERR, 6 (1), 36-41 (2017)

2. A.K. Sehra, Jr.W. Whitlow, Progress in Aerospace Sciences 40 (4-5), 199-235 (2004)

3. J. Goldmeer, V. Tangirala, A. Dean, Journal of Engineering for Gas Turbines and Power 130 (1) (2008)

4. P. Wolański, Proceedings of the Combustion Institute. 34 (1), 125-158 (2013)

5. A. Starikovskiy, N. Aleksandrov, Progress in Energy and Combustion Science 39 (1), 61-110 (2013)

6. Y. Wu, F. Ma, V. Yang, Journal of Propulsion and Power 19 (4), 556-567 (2003)

7. T. Endo, T. Yatsufusa, S. Taki, J. Kasahara, Science and Technology of Energetic Materials 65 (4), 103110 (2004)

8. N. Caldwell, A. Glaser, R. Dimicco, E. Gutmark, 43rd AIAA Aerospace Sciences Meeting and Exhibit - Meeting Papers, 1957-1968 (2005)

9. N. Caldwell, E. Gutmark, 44th AIAA/ASME/SAE/ASEE Joint Propulsion Conference and Exhibi

10. N. Caldwell, R. Brunet, A. Antoine, E. Gutmark, B. Drouin, 46th AIAA Aerospace Sciences Meeting and Exhibit 2008-012 (2008)

11. Dora E. "Fundamentals of Pulse Detonation Engine (PDE) and Related Propulsion Technology", Aerospace Engineering Consulting Arlington, TX.

12. Norris, G., "Pulse Power: Pulse Detonation Enginepowered Flight Demonstration Marks Milestone in Mojave," Aviation Week \& Space Technology, 168 (7) (2008)

13. Pulse Detonation Engine Flies Into History, Air Force Print News Today, (2008).

14. A. Yu. Tkachenko, V. S. Kuz'michev, E.P. Filinov, Y.A. Ostapyuk, I.N. Krupenich, IJMERR, 6 (1), 2835 (2016)

15. V. N. Rybakov, V. S. Kuz'michev, A. Yu. Tkachenko, I. N. Krupenich, Proceedings of the ASME Turbo Expo 2016: Turbomachinery Technical Conference and Exposition" 1 (2016) 